Brit. J. industr. Med., 1959, 16, 230.

\title{
PATTERNS OF SICKNESS ABSENCE IN A RAILWAY POPULATION
}

\author{
BY \\ CECIL GORDON, A. R. EMERSON, and DEREK S. PUGH \\ From the Department of Public Health and Social Medicine, University of Edinburgh
}

(RECEIVED FOR PUBLICATION OCTOBER 8, 1958)

This investigation was carried out in order to obtain morbidity statistics in a large industrial population with special reference to the effects of ageing.

The population chosen, the "railway research population," consisted of a sample of Scottish railwaymen, drawn from five of the eight areas in the Scottish Region of British Railways. Only certain occupational grades were studied.

Information was obtained over a period of one year by means of a detailed monthly return of $(a)$ sickness absence data and $(b)$ job changes. Indices of sickness absence were defined. The sickness absence experience of the railway research population was compared with that of other populations. It is a healthier group than the total insured population but differs in some respects from that of London Transport.

The nature of sickness absence within the railway research population was then studied. It was shown in all but one measure used that sickness tends to increase with age, the most important factor being the increase of long episodes. Examination of the frequency distribution of the duration of sickness episodes revealed that sickness absence tends to be taken in terms of weeks off rather than days off.

Analysis of the daily variation in sickness absence showed that the total absence rate increased from Monday to Friday. There was a well defined tendency for sickness to start on Mondays, and in longer episodes an additional tendency to start on Fridays. This was interpreted in terms of morale, both positive and negative.

Marked differences of the same order of magnitude as those due to age were noted in the sickness experience of the various grades, related to both conditions of work and responsibility.

The reasons for job changes were analysed and the grades to which men were transferred were identified. The choice of suitable grades for older workers was discussed.

It was concluded that working conditions might be important factors in the type of sickness absence experienced and that comparisons with other populations might be helpful in this context. More detailed work was also called for on the psychological as well as physical aspects of the work situation for both the individual and the grade.

The study of occupational health has, in general, been conducted by examination of the association between specific diseases and specific occupations through the medium of specific irritants. Studies of the aetiology of the dust diseases and of industrial bladder tumours are usually of this type. From the standpoint of the identification of pathological entities and the promulgation of preventive regulations, this method has had great success. This has led some to consider that the disease-centred approach is the only method available at present of assessing the health of the industrial worker. We dissent from the implications of this view and maintain that it is possible to make meaningful statements about health as a general concept, i.e., not only in terms of the absence of disease, but also, for example, in terms of the amount of sickness absence from work that is experienced by the individual. Sickness absence is a direct social concomitant of ill-health and thus its amount makes a good first approximation to a measurement of health. This sort of measurement would be particularly useful, for example, in comparing the relative healthiness of certain groups in the population. Of course, further refinement and other measures will have to be incorporated before a satisfactory, measurable definition of health is arrived at, but it seems to us that this method of successive approxi- 
mations, the validity of which can be measured, is a most useful one.

Partly because the emphasis has been on disease and partly because of difficulties in obtaining information, most past investigators have been concerned with the disease-centred approach, i.e., consideration of the incidence of diseases in terms of episodes or spells. As we are interested in the health and adaptation to work of people, we have so organized our data as to get a continuous record for each person over the period studied and our analysis will be predominantly person-centred.

We wish to present these data as a contribution to the small amount of person-centred information at present available.

\section{The Present Investigation}

The present investigation was undertaken in order to collect morbidity statistics for a large industrial group. In addition, it was to serve as preliminary material upon which to frame hypotheses and to allow for the isolation of subgroups for further study.

Relevant data were obtained on a sample of railwaymen in Scotland, which will be referred to as the "railway research population." The sample was restricted to five of the eight areas which comprise the Scottish Region of British Railways (the areas left out being the rural north). The railway research population was further limited to the nine largest of the 20 departments of the Scottish Region. Within these nine departments certain occupations (grades) were chosen.

A difficulty that arose was that the existing system of grades on the railways did not appear suitable for research purposes. Many of the grades were extremely heterogeneous and contained within themselves large variations in actual tasks. It was therefore agreed that there should be included a selection of 27 grades, each clearly defined and chosen by the Scottish Regional Establishment and Staff Office so as to be typical of the different occupations on the railways. Since the focus of interest was more especially on the older age groups, none of the grades with predominantly young workers, i.e., under 25 years of age, was included. The Regional Establishment and Staff Officer and his colleagues drew up a schedule in which the chosen grades are classified as to degrees of skill and responsibility, location and type of work, and other factors (Table 1).

In addition to the above, one further selection was made. The numbers in four of the 27 grades were too large to be dealt with and a sample of one in two was therefore taken from the grades of lengthman, locomotive fireman, signalman, and locomotive driver.

The railway research population thus consists of 14,074 men, which is $24 \%$ of all male employees on the railways in Scotland as given by the Registrar General's 1951 census.

After an initial census from which the age and length of service in present grade were obtained, a monthly return of all members of the railway research population was rendered to us for 12 months from April 1, 1955. This gave information on sickness absence and job changes.

Sickness Absence.-The sickness absence information consisted of: (1) Starting date of sickness episode (including day of the week); (2) finishing date of sickness episode (including day of the week); (3) the number of working days lost; (4) diagnosis; (5) hours worked in the week of the absence.

From this information the number, type and duration of sickness absences for each individual during the year were obtained and rates for various age and occupation groups were derived.

Two comments must be made on these data:

(1) The duration of an absence is given as the number of working days lost. Thus if a person is away for a week, this may mean the absence is counted as of five, six, or seven days' duration according to the number of days the absentee was scheduled to work during the particular week concerned. (Where an absence occurs when a half day is due to be worked, this is counted as a full day's absence.)

(2) In British Railways all people who are absent are required to provide a reason. If their absence is for three days or over, a medical certificate must be produced and in these cases the diagnosis is taken from the certificate. When the absence lasts for one or two days, the only admissible reason is still sickness, but the person's own description of the ailment is accepted. Thus all absence is "sickness absence" and we have for each occasion a "diagnosis" either as an item on a medical certificate or from the person concerned. It is appreciated that some of this short-term absence may be due to causes other than sickness.

Job Change.-The nature of and reasons for changes of jobs were also obtained.

\section{Results}

Percentage of Time Lost.-As a first overview of the health of the railway research population, we shall consider the percentage of time lost due to sickness.

The total number of days lost throughout the year was obtained. On the basis of a five and a half 
TABLE 1

REPRESENTATIVE RAILWAY GRADES

\begin{tabular}{|c|c|c|c|}
\hline \multicolumn{2}{|c|}{ Manual } & \multicolumn{2}{|c|}{ Sedentary } \\
\hline 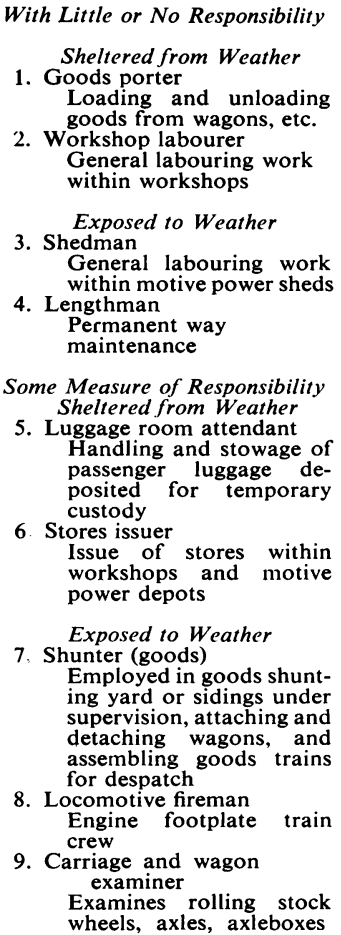 & $\begin{array}{l}\text { Carrying Considerable Degree of } \\
\text { Responsibility } \\
\text { Sheltered from Weather } \\
\text { 10. Signalman } \\
\text { Manipulating signallevers } \\
\text { in signal box controlling } \\
\text { section of the line } \\
\text { Responsible for safe con- } \\
\text { duct of trains within his } \\
\text { section } \\
\text { 11. Locomotive fitter } \\
\text { Artisan employed in } \\
\text { workshops and motive } \\
\text { power sheds } \\
\text { Artisan employed in } \\
\text { workshops on the fashion- } \\
\text { ing of patterns necessitat- } \\
\text { ing a high degree of } \\
\text { accuracy } \\
\text { Exposed to Weather } \\
\text { 12. Pattern maker } \\
\text { Engine footplate train } \\
\text { crew. Thorough know- } \\
\text { ledge of signalling } \\
\text { arrangements, rules, and } \\
\text { regulations } \\
\text { 14. Ganger } \\
\text { Permanent way track } \\
\text { maintenance. Has charge } \\
\text { of length gang of between } \\
\text { five and eight men. } \\
\text { Equivalent to working } \\
\text { foreman } \\
\text { Maintenance of electrical } \\
\text { signal apparatus, tele- } \\
\text { phone lines, and tele- } \\
\text { communication installa- } \\
\text { tions } \\
\text { Usually has one or more } \\
\text { shunters under him and } \\
\text { has to give directions }\end{array}$ & $\begin{array}{l}\text { Routine Work-Little or No } \\
\text { Initiative Required } \\
\text { 17. Timekeeper } \\
\text { Employed in workshops } \\
\text { and motive power depots, } \\
\text { etc. Maintains time re- } \\
\text { cords and does other rou- } \\
\text { tine clerical work } \\
\text { Employed in workshops } \\
\text { Purely routine work } \\
\text { 18. Shop officeman } \\
\text { 19. Clerk } \\
\text { Routine clerical work in } \\
\text { all departments } \\
\text { More or Less Routine but Requir- } \\
\text { ing Some Measure of Initiative } \\
\text { 20. Control staff } \\
\text { Employed at static control } \\
\text { points, supervising and re- } \\
\text { gulating movements of } \\
\text { rolling stock and traffic on } \\
\text { running lines } \\
\text { Normally required to } \\
\text { 21. Senior clerk } \\
\text { supervise small number } \\
\text { of clerks }\end{array}$ & $\begin{array}{l}\text { d Supervisory } \\
\text { nitiative and Mental Responsibility } \\
\text { Weather } \\
\text { 26. Yard inspector } \\
\text { Supervision of shunting } \\
\text { yard staff. Responsible } \\
\text { for shunting operations } \\
\text { including the assembling, } \\
\text { despatch, and staging of } \\
\text { goods trains } \\
\text { 27. Permanent way inspector } \\
\text { Supervision of permanent } \\
\text { way maintenance. Has } \\
\text { control of several gangs } \\
\text { in a particular area }\end{array}$ \\
\hline
\end{tabular}

day week, the total man-days available for work were calculated and thus the percentage of time lost. The figures are:

Man-days lost in the year

Total man-days available

$$
\begin{array}{lr}
. & 116,742 \\
. & 4,025,164
\end{array}
$$$$
\text { Proportion of time lost .. } \quad . . \quad 2.90 \%
$$

We compare this percentage with an equivalent figure derived from London Transport Executive (1956) on certain groups of their male employees. Their returns relate to a seven-day week and their figures are as follows:

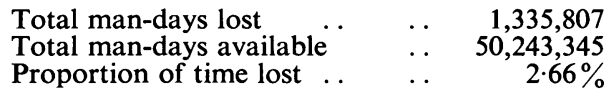

The two estimates of the percentage of time lost are of the same order of magnitude. As these two proportions are only very general estimates, we shall not attempt any more direct comparisons (which would involve consideration of differences in the method of compiling the data and would entail an age standardization), but instead we shall compare age trends in the two populations. This is a more useful way of considering the data.

A further general comparison can be made with data derived from the sickness and injury benefit for the whole country given by the Ministry of Pensions and National Insurance (1956) report. This gives the days lost for sickness episodes of four days or more:

Total man-days lost.. $\quad \ldots \quad 201.77$ million

Total man-days available .. $\quad 5,256.00$ million

Proportion of time lost $\ldots \quad 3.8 \%$

The comparative figures for the railway research population are as follows:

Total man-days lost (due to episodes

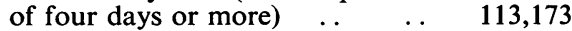

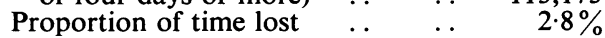

The proportion of time lost in the general population is higher than that in the railway research population. The extent of the effect of age is discussed later in regard to episode rate.

Indices of Sickness Absence.-We shall use the indices of sickness absence defined below. In all cases the population is that of the railway research population at the initial census. The corresponding nomenclature of the General Register Office's (1954) pamphlet is shown, but it must be appreciated that 
to be directly comparable our own rates must be subjected to slight adjustment because of some differences in definition.

(1) Sick Person Rate $(=0 \cdot 29)$.- The number of persons who are absent sick at some time during the year divided by the number in the population (General Register Office's period prevalence rate (persons)).

(2) Episode Rate $(=0.46)$. - The number of episodes or spells of sickness which are current at some time during the year, divided by the number in the population (General Register Office's period prevalence rate (spells)).

(3) Average Duration per Person (= 8.29 Days Lost in the Year).-The total duration within the year of all episodes of sickness that occurred wholly or partly within the year divided by the number in the population (General Register Office's average duration per person).

(4) Average Duration per Sick Person (=28.27 Days Lost in the Year).-The total duration within the year of all episodes of sickness that occurred wholly or partly within the year divided by the number of persons having at least one episode during the year (General Register Office's average duration per sick person).

(5) Average Duration per Episode (= 17.89 Days).-The total duration within the year of all episodes that occurred wholly or partly within the year divided by the number of such episodes (General Register Office's average duration per spell).

(6) Average Number of Episodes per Sick Person (= 1.58 Episodes).-The number of episodes of sickness which are current at some time during the year, divided by the number of people who are sick at some time during the year. (There is no General Register Office equivalent.)

We shall use each of these various indices at suitable times. For our own person-centred orientation, the two most useful indices to characterize a population are the sick person rate and the average duration per episode. For the purpose of obtaining comparisons with other work, we have also used the episode rate on a number of occasions.
Changes with Age in Railway Research Population.-Table 2 gives the values at various age ranges of the indices described above. (It should be noted that the 15-to-19-year-old group contains only 11 men and the rates for this age group are therefore not reliable.)

In general, it will be seen that all the indices, except the average number of episodes per sick person, have a definite age trend towards increasing sickness with age. It is, however, in those rates which incorporate duration that the age trend is the largest; for example, the average duration per person rises from four days lost during the year at age 20 to 24 to 15 days at 60 to 64 .

Three general features of these age-specific rates may be noted.

(1) In the indices which do not incorporate duration, i.e., the sick person rate and the episode rate, there is a mode at age 20 to 24 . The rates then fall until age 35 to 39 and rise again in the later ages. We have as yet no explanation for this phenomenon.

(2) In the indices which incorporate duration, there is a marked increase with age. The fact that the change in the rates between ages 55 and 59 and 60 and 64 is much smaller than would be expected on this basis requires comment. Our hypothesis is that this lack of increase in the 60 to 64 age group is due to a separation of the more seriously sick people from the labour force. This is substantiated by a consideration of Table 3, derived from the job change data of the railway research population. This shows the percentage of railwaymen leaving the service due to health reasons or death. It will be seen that there is a big increase in the 55 to 59 age group. The majority of these separations were associated with some sickness absence during the year and would thus have been very likely to contribute to the amount of sickness absence at the 60 to 64 age group had they remained in employment.

For this reason it is maintained that at age 60 to 64 the employed railway population has a bias in favour of the healthier worker as compared with

TABLE 2

SICKNESS EXPERIENCE BY AGE IN A RAILWAY RESEARCH POPULATION

\begin{tabular}{|c|c|c|c|c|c|c|c|c|c|c|c|c|}
\hline \multirow{2}{*}{ Index } & \multicolumn{12}{|c|}{ Age Groups } \\
\hline & $15-$ & $20-$ & $25-$ & $30-$ & $35-$ & $40-$ & $45-$ & $50-$ & $55-$ & $60-$ & $65+$ & Total \\
\hline $\begin{array}{l}\text { Sick person rate } \\
\text { Episode rate } \\
\text { Average duration per person (days lost in the } \\
\text { year) } \\
\text { Average duration per sick person (days lost in } \\
\text { the year) } \\
\text { Average duration per episode (days) } \\
\text { Average number of episodes per sick person }\end{array}$ & $\begin{array}{l}0.18 \\
0.27 \\
0.45 \\
2.50 \\
1.67 \\
1.50\end{array}$ & $\begin{array}{r}0 \cdot 30 \\
0 \cdot 49 \\
4 \cdot 29 \\
14 \cdot 33 \\
8 \cdot 71 \\
1 \cdot 65\end{array}$ & $\begin{array}{r}0 \cdot 27 \\
0 \cdot 42 \\
4 \cdot 29 \\
15 \cdot 62 \\
10 \cdot 33 \\
1 \cdot 51\end{array}$ & $\begin{array}{r}0 \cdot 26 \\
0.41 \\
4 \cdot 85 \\
18.97 \\
11 \cdot 84 \\
1.60\end{array}$ & $\begin{array}{r}0 \cdot 26 \\
0.40 \\
5 \cdot 10 \\
19 \cdot 91 \\
12 \cdot 71 \\
1.57\end{array}$ & $\begin{array}{l}0.27 \\
0.42 \\
\\
5.89\end{array}$ & $\begin{array}{l}0.28 \\
0.48 \\
\\
8 \cdot 12\end{array}$ & $\begin{array}{l}0.31 \\
0.48 \\
\\
9.52\end{array}$ & $\begin{array}{r}0.33 \\
0.52 \\
13.78\end{array}$ & $\begin{array}{r}0.34 \\
0.53 \\
15.04\end{array}$ & $\begin{array}{l}0.27 \\
0.33 \\
\\
9.75\end{array}$ & $\begin{array}{l}0.29 \\
0.46 \\
8.29\end{array}$ \\
\hline $\mathbf{N}=$ & 11 & 1,112 & 1,755 & 1,644 & 1,143 & 1,212 & 1,429 & 2,380 & 2,136 & 1,201 & 51 & 14,074 \\
\hline
\end{tabular}


TABLE 3

PERCENTAGE OF RAILWAY RESEARCH POPULATION LEAVING SERVICE AT EACH AGE FOR HEALTH REASONS (INCLUDING DEATHS AND FATAL INJURIES)

\begin{tabular}{c|c|c|c|c|c|c|c|c|c}
\hline \multicolumn{8}{c}{ Age Groups } \\
\hline $20-$ & $25-$ & $30-$ & $35-$ & $40-$ & $45-$ & $50-$ & $55-$ & $60-64$ & All \\
\hline 0 & 0.2 & 0.1 & 0.3 & 0.5 & 0.8 & 0.9 & 2.1 & 2.9 & 0.9 \\
\hline
\end{tabular}

the notional total railway population (working, retired, or dead).

(3) There is a sharp drop in the rates for all measures except the average duration per episode in the 65 years and over age group. This would appear to be due to the fact that the normal age for retirement from railway service is 65 and it is only exceptionally that men are allowed to remain at work. It is obvious that those who do remain are a highly selected group in regard to health and adaptation to work.

Comparisons with Other Populations.-The comparisons with London Transport are shown in Figs. 1 and 2. London Transport regard all episodes of six months or over as being of six months only; and for all comparisons our own figures have been corrected on this basis. From these it is immediately obvious that the railway research population has a different pattern of sickness absence, having a much lower episode rate $(0.46$ as compared with 0.86$)$, counterbalanced by a higher average duration per episode (16.94 days against 11.28$)$, and this is true in all age groups. This is a striking and interesting difference and we should like to be able to pursue it further. To do this it would be necessary to compare a relevant occupation group in the first instance. A comparison of diagnostic categories would also be valuable. This has been done for one group, namely clerks (Pugh, Gordon, and Lévy, 1959).

Comparison with the total insured population is given in Fig. 3. In this case all episodes of three days and under are excluded, and our own data have been re-corrected in this respect. We again find that the episode rate for the railway research population is below that for the insured population at all ages (the figures for all ages combined are 0.30 as against 0.39 ). This would indicate that the railway staff are healthier than the population generally, unless the durations per episode outweigh this, which seems improbable. (Figures for average duration per episode are not available from the Ministry of Pensions and National Insurance.)

Fig. 1 shows that there is more variation with age in the episode rate for London Transport workers than with thề railway research population. When the comparison is made with the total insured population (Fig 3 , only episodes of three days and over being considered) it is clear that there is a more

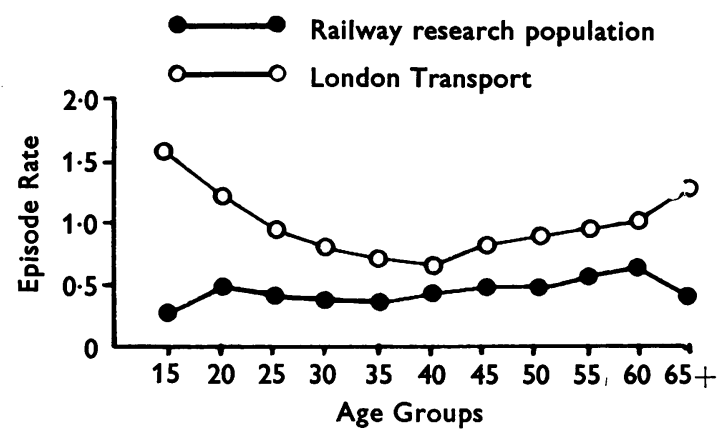

Fig. 1.-Episode rate.

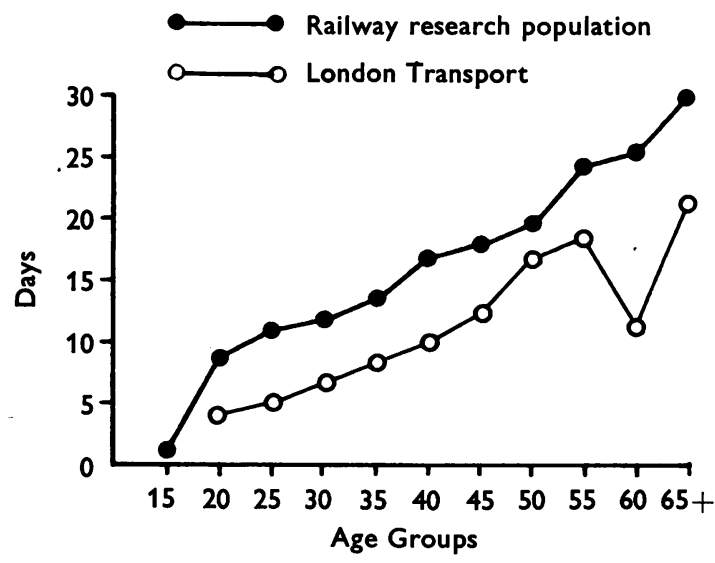

FIG. 2.-Average duration per episode.

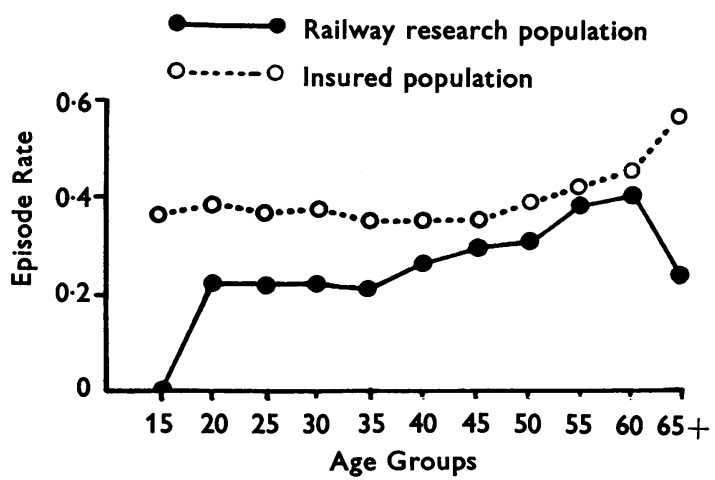

Fig. 3.-Comparison with insured population. 
direct relationship between age and episode of sickness in the railway research population. The characteristic drop in the curves beyond the age of 60 is again to be noticed for the railway research population, but not for London Transport or the total insured population.

Duration of Episodes.-Fig. 2 shows that the average duration per episode becomes consistently longer with age in both London Transport and the railway research population. The length of episodes varied from one day to the whole year under consideration. An examination of the frequency distribution of the different episode durations was carried out. It was immediately apparent that the distribution was cyclic. The number of one-day episodes was large and the curve then fell steeply to four days. It then rose again for episodes of five and six days' duration. When the curve was followed through, it was seen that there was a peak at each multiple of five or six days. This cyclic pattern continued up to episode durations of the full year (Fig. 4).

It should be remembered that these episode durations are in working days lost and that the working week in British Railways is of five or five and a half days, five and a half days being counted as six for absence purposes (see above). Bradford Hill (1929) has demonstrated a somewhat similar cyclic pattern. He also found a tendency for sickness episodes to last for a week and, since he counted a week as of seven days' duration, this produced peaks at intervals of six, 13, 20 days, etc. He also found a lesser tendency for sickness episodes to end on the same day as they started, i.e., to last eight days, and this produced lesser peaks at intervals of eight, 15, 22 days, etc. It is thus apparent that the cyclic nature of the distribution is caused by the fact that sickness absence periods (once one gets beyond the very short one- or two-day episodes) are more usually taken in terms of weeks off rather than days off.

There appeared also to be a secondary monthly cycle.

Type of Episode.-The recurrence of peaks at weekly and monthly intervals has provided a rationale for dividing the episodes into duration types; for example, up to a week, up to one month, up to two months, etc. To economize on types and because of the smallness of numbers, some amalgamations were made. But absences of up to two days' duration, since they do not require a medical certificate, have been considered separately. The final classification is thus as follows:

\begin{tabular}{l|c}
\hline Type of Episode & Duration \\
\hline Uncertified & 1 or 2 days \\
Casual & 3 to 6 days \\
Short & 7 to 24 days \\
Medium & 25 to 72 days \\
Long & 73 days and over \\
\hline
\end{tabular}

Uncertified episodes refer to very short durations; casual episodes to those up to the week's peak; short to those up to the month's peak; medium to those up to the three month's peak; long episodes are those over three months.

Percentage Incidence of Types of Episodes.-The last two columns of Table 4 give the percentage incidence of types of episodes for the whole railway research population, together with the percentage of time lost due to each type of episode. In general, it will be seen that the percentages go in opposite directions. Whereas uncertified sickness provides the largest percentage of episodes, it provides the smallest amount of days lost and, while long sicknesses are smallest in number, they account for the highest proportion of days lost.

The breakdown of the percentage incidence of types of episodes by age groups is also given in Table 4. This demonstrates very strikingly the changing patterns of sickness absence with age. There is considerably less uncertified and casual absence among the older groups and considerably more medium or long episodes. Thus the increase in average duration per person with age (see Table 2) is not due to an increase in all types of episodes but to a selective increase in the longer durations.

Daily Variations in Sickness Absence.-There have been a number of studies of daily variations in sickness absence and many of these have concentrated on the "blue Monday" effect. This is the fact

TABLE 4

PERCENTAGE INCIDENCE OF TYPES OF EPISODE BY AGE

\begin{tabular}{|c|c|c|c|c|c|c|c|c|c|c|c|c|}
\hline & \multicolumn{10}{|c|}{ Age Groups } & \multirow{2}{*}{$\begin{array}{c}\text { Percentage } \\
\text { of Total } \\
\text { Episodes }\end{array}$} & \multirow{2}{*}{$\begin{array}{c}\text { Percentage } \\
\text { of Time } \\
\text { Lost }\end{array}$} \\
\hline & $20-$ & $25-$ & $30-$ & $35-$ & $40-$ & $45-$ & $50-$ & $55-$ & $60-$ & $65+$ & & \\
\hline $\begin{array}{l}\text { Uncertified } \\
\text { Casual } \\
\text { Short } \\
\text { Medium } \\
\text { Long }\end{array}$ & $\begin{array}{r}45 \cdot 4 \\
25 \cdot 4 \\
22 \cdot 4 \\
5 \cdot 5 \\
1 \cdot 1\end{array}$ & $\begin{array}{r}36 \cdot 6 \\
24 \cdot 3 \\
30 \cdot 5 \\
7 \cdot 3 \\
1 \cdot 2\end{array}$ & $\begin{array}{r}39 \cdot 1 \\
20 \cdot 6 \\
30 \cdot 0 \\
7 \cdot 7 \\
2 \cdot 1\end{array}$ & $\begin{array}{r}39 \cdot 2 \\
21 \cdot 6 \\
27 \cdot 0 \\
8 \cdot 9 \\
4 \cdot 1\end{array}$ & $\begin{array}{r}32 \cdot 4 \\
17 \cdot 4 \\
34 \cdot 3 \\
11 \cdot 5 \\
4 \cdot 5\end{array}$ & $\begin{array}{r}32 \cdot 5 \\
17 \cdot 2 \\
30 \cdot 2 \\
15 \cdot 5 \\
4 \cdot 0\end{array}$ & $\begin{array}{r}27 \cdot 3 \\
20 \cdot 0 \\
32 \cdot 0 \\
14 \cdot 9 \\
.6 \cdot 0\end{array}$ & $\begin{array}{r}21 \cdot 1 \\
18 \cdot 3 \\
33 \cdot 3 \\
17 \cdot 8 \\
9 \cdot 5\end{array}$ & $\begin{array}{l}20.1 \\
15.0 \\
33.9 \\
19.8 \\
11.2\end{array}$ & $\begin{array}{l}17 \cdot 6 \\
17 \cdot 7 \\
29 \cdot 4 \\
17 \cdot 7 \\
17 \cdot 7\end{array}$ & $\begin{array}{r}31 \cdot 1 \\
19 \cdot 8 \\
30 \cdot 8 \\
12.9 \\
5 \cdot 4\end{array}$ & $\begin{array}{r}2 \cdot 36 \\
5 \cdot 31 \\
22 \cdot 40 \\
31 \cdot 50 \\
38 \cdot 42\end{array}$ \\
\hline $\mathrm{N}=100 \%=$ & 548 & 729 & 673 & 459 & 513 & 681 & 1,153 & 1,119 & 632 & 17 & 6,527 & 116,743 \\
\hline
\end{tabular}



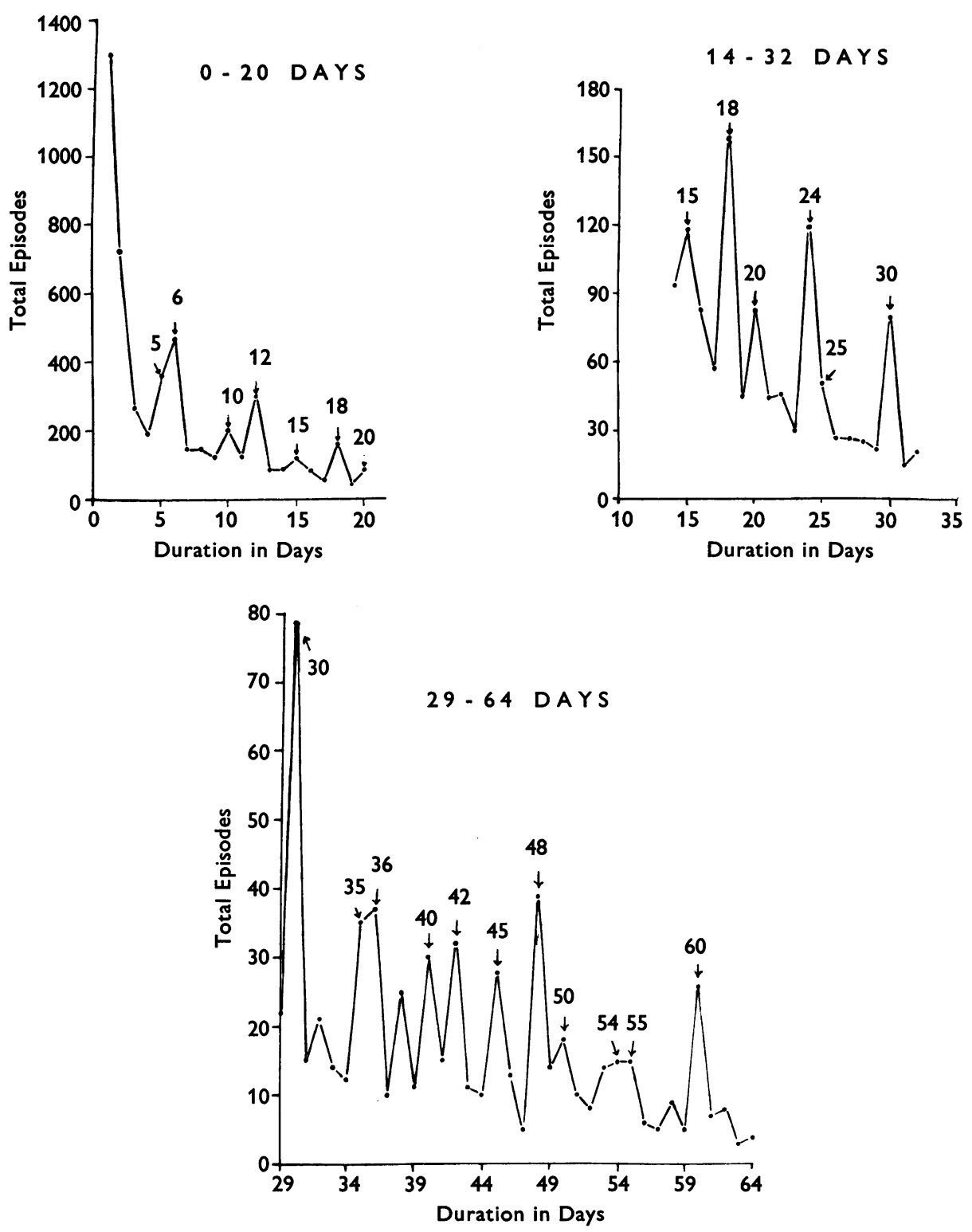

FIG. 4.-Frequency of episodes by duration (periodicity).

that the absence rate, i.e., the percentage of mandays lost, is highest on a Monday and diminishes steadily during the week to its lowest point on a Friday. If one accepts the lower Friday rate as being a better estimate of "real" sickness, then it is usual to attribute the excess of Monday's absence over Friday's as being due to such factors as low morale.

Our own data on this question are summarized in Table 5. Only Monday to Friday is considered, since these days are worked by all grades.

It will be seen that for all sickness, the absence rate increases from Monday to Friday, and this is especially true of episodes of three days and over requiring medical certificates (certified sickness). This is generally considered to indicate high morale and a positive attitude to work. The rise in the rate may be explained by the effects of increasing fatigue 
TABLE 5

DAILY VARIATIONS IN AMOUNT OF SICKNESS ABSENCE (PERCENTAGE OF MAN-DAYS LOST)

\begin{tabular}{l|c|c|c|c|c}
\hline & Mon. & Tues. & Wed. & Thur. & Fri. \\
\cline { 2 - 3 } All sickness & $2 \cdot 73$ & $2 \cdot 77$ & $2 \cdot 80$ & $2 \cdot 81$ & $2 \cdot 84$ \\
Uncertified sickness & 0.09 & 0.08 & 0.07 & 0.06 & 0.05 \\
Certified sickness & 2.64 & 2.69 & $2 \cdot 73$ & 2.75 & 2.79 \\
\hline
\end{tabular}

and general strain as the week wears on, causing greater likelihood of succumbing to sickness.

We have also considered the daily variations in the five types of episode durations (see above). The general upward trend is reflected in all of them except the uncertified sickness. This shows a typical "blue Monday" effect in that the rate decreases from Monday to Friday (see Table 5). This contrasting slope suggests that uncertified absences, i.e., those of one or two days' duration, are caused by different factors from longer episodes. Poor morale effects and reluctance to return to work after the weekend break may be relevant here. Behrend (1951) cites a similar result from a study of absentee rates among coal-miners in a normal working week in 1943. "The involuntary (unavoidable) rate shows a rising weekly absence curve, while the voluntary absence rate on the average shows a fall from Monday to Friday." There appears to be some

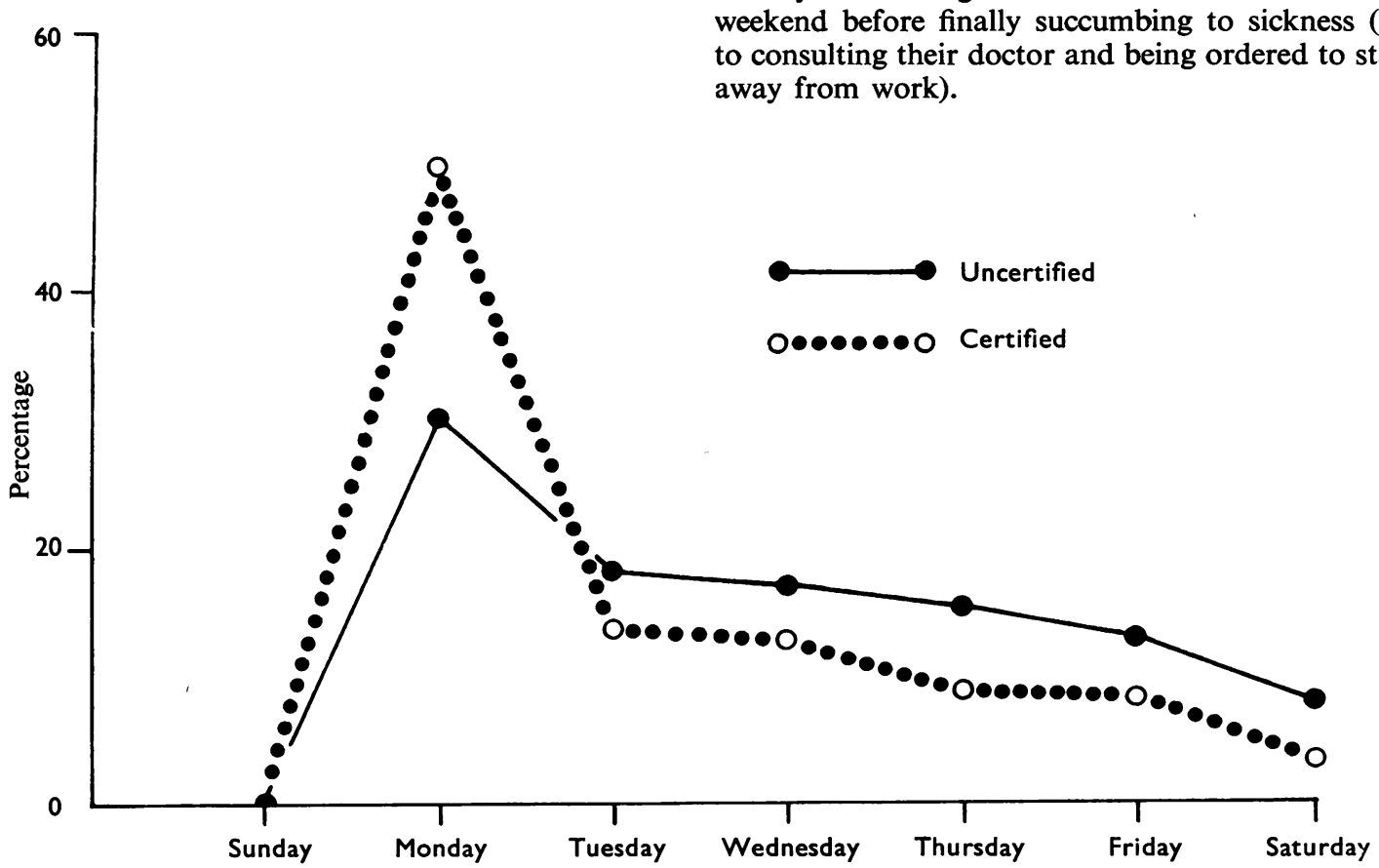

FIG. 5.-Comparison of starting day for certified and uncertified duration types.

inconsistency in characterizing populations in this way.

The Day of Starting Sickness.-There is another way of looking at these phenomena which bears some resemblance to that used by Bradford Hill (op. cit.). We have explored this topic by way of variations in the day of starting sickness. Table 6 shows that $45 \%$ of all episodes were started on a Monday. The breakdown of the various duration types is also given and it will be seen that more episodes of all types begin on a Monday than on any other day. (However, considerably more casual, short, medium, and long episodes start on this day than uncertified ones.) We have therefore combined all except the uncertified durations into one category, referred to as "certified episodes" (Fig. 5). As we have demonstrated, there is a tendency for these types of sickness absence to be taken in terms of weeks off rather than days off: it thus follows that since most sickness absence starts on a Monday, most must end on a Saturday, i.e., most railwaymen return to work after an episode of sickness on a Monday. Bradford Hill noted a similar tendency in relation to day of starting and day of ending sickness absence.

The fact that half the certified episodes begin on a Monday strongly supports a high morale factor. It would appear that a disproportionate number of railwaymen manage to remain at work until the weekend before finally succumbing to sickness (or to consulting their doctor and being ordered to stay away from work). 
Table 6 and Fig. 6 show an interesting trend with regard to the percentages of episodes starting on a Friday in the different types comprising certified episodes. It will be seen that a very small percentage of casual episodes start on a Friday; this, however, may well be related to pay day; a rather larger percentage of short episodes (comparable to the number of short episodes starting on Tuesday, Wednesday, and Thursday); and for medium and long episodes Friday is the most frequent day (after Monday) for starting a sickness. It would appear that as we move into the longer durations, it gets progressively more difficult for the man to remain at work until the weekend and increasing numbers succumb before this time. This is again evidence of high morale.

The effect of age on day of starting sickness has been examined, but no clear trends have been found beyond that expected because of the decreasing incidence of uncertified episodes in the older age groups.

The importance of considering the day of starting sickness together with the major support which it gives to the existence of a factor of high morale amongst railwaymen prompts us to revise the interpretation of the "blue Monday effect" based on daily absence rates in uncertified sickness. If there is a tendency to start sickness on Mondays (Table 6) and this is due to high morale, then the absences due to uncertified sickness will be sui generis higher on Mondays or Tuesdays than during the rest of the week. On this reasoning the decrease in absences from Monday to Friday may be due to high morale and not to low morale.

Clearly the examination of such problems must pay attention to variation in the days of starting sickness as well as daily variation in absence rates.

The Morale of Railwaymen.-In the preceding discussion we have suggested interpretations of the results in the morale terms commonly used by labour economists in this field. But further work is required in order to substantiate any hypotheses. Morale and effects of strain are psychological concepts and must be investigated in individual

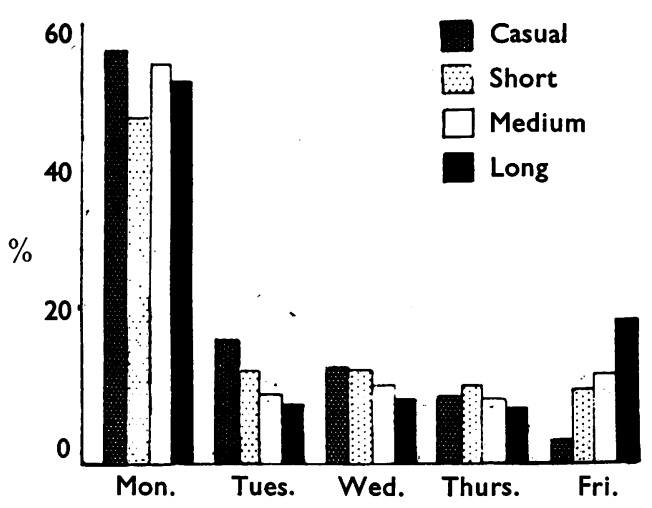

Fig. 6.-Day of starting sickness for certified duration types.

behaviour and attitude before they can be accepted as satisfactory explanations.

Sickness Absence Experience in the Various Occupations (Grades).-So far we have considered trends for the whole of the railway research population by age. We now come to consider differences in the various occupations or grades. As there are age trends in the population and varying age distributions in the grades, it is necessary to standardize for age. However, many age groups are often represented only slightly or not at all in some grades; for example, the lower age groups are not represented in the supervisory grades and the higher age groups are only slightly represented among the firemen. Thus the "indirect" method of standardization (Registrar General, England and Wales, Report, 1911) has had to be used. By the indirect method of standardization, the favourable or unfavourable nature of the age distribution of a particular grade, compared with the total population, is assessed in relation to sickness experience, and the recorded total sickness absence is increased or decreased as the case may be. The method is in fact one of handicap. The assessment of this handicap is as follows. The age specific sickness absence rate for the railway research population is

TABLE 6

DAY OF STARTING SICKNESS

\begin{tabular}{|c|c|c|c|c|c|c|c|c|}
\hline \multirow{2}{*}{ Type of Episode } & \multicolumn{7}{|c|}{ Percentage of Episodes Starting on a: } & \multirow{2}{*}{$(\mathrm{N}=100 \%)$} \\
\hline & Sunday & Monday & Tuesday & Wednesday & Thursday & Friday & Saturday & \\
\hline Total & 1.90 & $45 \cdot 00$ & $14 \cdot 48$ & $13 \cdot 56$ & 11.08 & $10 \cdot 13$ & 4.86 & 6,527 \\
\hline $\begin{array}{l}\text { Uncertified } \\
\text { Casual } \\
\text { Short } \\
\text { Medium } \\
\text { Long }\end{array}$ & $\begin{array}{l}0.30 \\
0.31 \\
1.59 \\
1.43 \\
1.43\end{array}$ & $\begin{array}{l}29 \cdot 85 \\
56 \cdot 53 \\
47.64 \\
54 \cdot 52 \\
52 \cdot 15\end{array}$ & $\begin{array}{r}17.64 \\
16.91 \\
12.77 \\
9.88 \\
8.02\end{array}$ & $\begin{array}{r}16 \cdot 85 \\
13 \cdot 20 \\
12 \cdot 72 \\
10 \cdot 36 \\
8 \cdot 31\end{array}$ & $\begin{array}{r}14 \cdot 78 \\
8 \cdot 80 \\
10 \cdot 58 \\
8 \cdot 45 \\
7 \cdot 16\end{array}$ & $\begin{array}{r}12.32 \\
3.09 \\
9.99 \\
12.02 \\
19.77\end{array}$ & $\begin{array}{l}8 \cdot 28 \\
1 \cdot 16 \\
4 \cdot 72 \\
3 \cdot 33 \\
3 \cdot 15\end{array}$ & $\begin{array}{r}2,030 \\
1,295 \\
2,013 \\
840 \\
349\end{array}$ \\
\hline Certified & $1 \cdot 18$ & $49 \cdot 61$ & 13.05 & $12 \cdot 07$ & $9 \cdot 41$ & $9 \cdot 14$ & $3 \cdot 31$ & 4.497 \\
\hline
\end{tabular}


TABLE 7

AGE STANDARDIZED RATES

\begin{tabular}{|c|c|c|c|c|c|c|}
\hline \multirow[b]{2}{*}{ Grade } & \multicolumn{3}{|c|}{ Sick Person Rate } & \multicolumn{3}{|c|}{ Average Duration per Episode (days) } \\
\hline & $\underset{\text { Rate }}{\text { Actual }}$ & $\begin{array}{c}\text { Age } \\
\text { Standardized } \\
\text { Rate }\end{array}$ & Rank & $\begin{array}{c}\text { Actual } \\
\text { Duration }\end{array}$ & $\begin{array}{c}\text { Age } \\
\text { Standardized } \\
\text { Duration }\end{array}$ & Rank \\
\hline $\begin{array}{l}\text { 1. Goods porter } \\
\text { 2. Workshop labourer } \\
\text { 3. Shedman } \\
\text { 4. Lengthman } \\
\text { 5. Luggage room attendant } \\
\text { 6. Stores issuer } \\
\text { 7. Shunter (goods) } \\
\text { 8. Locomotive fireman } \\
\text { 9. Carriage and wagon examiner } \\
\text { 10. Signalman } \\
\text { 11. Locomotive fitter } \\
\text { 12. Pattern maker } \\
\text { 13. Locomotive driver } \\
\text { 14. Ganger } \\
\text { 15. Telegraph lineman } \\
\text { 16. Head shunter } \\
\text { 17. Timekeeper } \\
\text { 18. Shop officeman } \\
\text { 19. Clerk } \\
\text { 20. Control staff } \\
\text { 21. Senior clerk } \\
\text { 22. Chief controller } \\
\text { 23. Chief clerk } \\
\text { 24. Stationmaster } \\
\text { 25. Running shift foreman } \\
\text { 26. Yard inspector } \\
\text { 27. Permanent way inspector }\end{array}$ & $\begin{array}{l}0 \cdot 46 \\
0 \cdot 44 \\
0 \cdot 27 \\
0 \cdot 27 \\
0 \cdot 07 \\
0 \cdot 40 \\
0 \cdot 33 \\
0 \cdot 22 \\
0 \cdot 23 \\
0 \cdot 20 \\
0 \cdot 29 \\
0 \cdot 21 \\
0 \cdot 22 \\
0 \cdot 20 \\
0 \cdot 26 \\
0 \cdot 23 \\
0 \cdot 27 \\
0 \cdot 42 \\
0 \cdot 40 \\
0 \cdot 42 \\
0 \cdot 37 \\
0 \cdot 43 \\
0 \cdot 33 \\
0 \cdot 26 \\
0 \cdot 32 \\
0 \cdot 53 \\
0 \cdot 22\end{array}$ & $\begin{array}{l}0 \cdot 43 \\
0 \cdot 37 \\
0 \cdot 27 \\
0 \cdot 27 \\
0 \cdot 06 \\
0 \cdot 37 \\
0 \cdot 34 \\
0 \cdot 24 \\
0 \cdot 23 \\
0 \cdot 20 \\
0 \cdot 29 \\
0 \cdot 20 \\
0 \cdot 21 \\
0 \cdot 19 \\
0 \cdot 27 \\
0 \cdot 24 \\
0 \cdot 25 \\
0 \cdot 41 \\
0 \cdot 40 \\
0 \cdot 44 \\
0 \cdot 35 \\
0.43 \\
0 \cdot 30 \\
0 \cdot 25 \\
0 \cdot 29 \\
0 \cdot 48 \\
0 \cdot 20\end{array}$ & $\begin{array}{c}3 \frac{1}{2} \\
8 \\
15 \\
15 \\
27 \\
7 \\
10 \\
20 \\
21 \\
24 \frac{1}{2} \\
12 \frac{1}{2} \\
23 \\
22 \\
26 \\
15 \\
19 \\
17 \\
5 \\
6 \\
2 \\
9 \\
3 \frac{1}{2} \\
11 \\
17 \\
12 \frac{1}{2} \\
1 \\
24 \frac{1}{2}\end{array}$ & 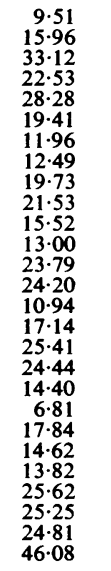 & $\begin{array}{r}9 \cdot 48 \\
15 \cdot 21 \\
29 \cdot 34 \\
22 \cdot 36 \\
26 \cdot 66 \\
17 \cdot 17 \\
15 \cdot 74 \\
21 \cdot 29 \\
20 \cdot 75 \\
20 \cdot 57 \\
17 \cdot 35 \\
12 \cdot 52 \\
18 \cdot 61 \\
19 \cdot 32 \\
11 \cdot 09 \\
18.96 \\
20 \cdot 39 \\
21 \cdot 47 \\
16.64 \\
10 \cdot 02 \\
14 \cdot 13 \\
13.95 \\
10 \cdot 73 \\
22 \cdot 54 \\
19.86 \\
18.96 \\
35.60\end{array}$ & $\begin{array}{r}27 \\
19 \\
2 \\
5 \\
3 \\
17 \\
20 \\
7 \\
8 \\
9 \\
16 \\
23 \\
15 \\
12 \\
24 \\
13 \frac{1}{2} \\
10 \\
6 \\
18 \\
26 \\
21 \\
22 \\
25 \\
4 \\
11 \\
13 \frac{1}{2} \\
1\end{array}$ \\
\hline Total railway research population & $0 \cdot 29$ & $0 \cdot 29$ & - & $17 \cdot 89$ & $17 \cdot 89$ & - \\
\hline
\end{tabular}

applied to the particular grade and the numbers which would have occurred are summed over all age groups. This calculated figure for total sickness absence is then related to the actual. This figure is the standardizing factor which, when multiplied by the crude rate, gives the age standardized rate.

Considering the standardized rate of the two measures shown in Table 7 , we see that there are wide grade variations on both of them, and indeed on the remaining indices not given in the table. The grade of yard inspector has the highest sick person rate $(0.48)$ and the range goes from there to 0.06 for luggage room attendant, the rate for the whole railway research population being $0 \cdot 29$. The average duration per episode ranges from $35 \cdot 6$ days (permanent way inspector) to 9.4 days (goods porter) with 17.89 days for the whole population.

The figure given in Table 7 show clearly the large amount of variation due to differences in occupation. These seem to be quite as striking as the differences due to age.

The Relation between the Measures. - In characterizing a grade as being "sick" or "well" two measures seemed to be the most suitable; the sick person rate and the average duration per episode. These give respectively the proportion of men in the grade who have had a sickness and the average length of each episode. These measures between them incorporate the following variables for each grade: $(a)$ Number of persons, $(b)$ number of sick persons, $(c)$ number of episodes, and $(d)$ number of days lost. Thus they cover implicitly average duration per person, average duration per sick person, and the episode rate. In addition, they are logically independent, the first being based on $(a)$ and $(b)$ above and the second on $(c)$ and $(d)$. They have therefore been used as the two dimensions of sickness absence along which grades can be rated. Table 8 is a contingency table based on the quartiles for these two rates.

An interesting result was obtained when the two measures were correlated and the Spearman rank correlation (rho) was found to be $-0 \cdot 53$. Thus there appears to be a very strong tendency for grades which are rated as sick on one measure to be rated as well on the other. This is demonstrated by a consideration of Table 8 , where it will be seen that the first quadrant (the upper right hand quadrant representing those grades which are sick on both measures) and the third quadrant (those which are well on both measures) contain only three grades each, whereas the remaining second and fourth quadrants, i.e., sick on one and well on the other, contain 11 and 10 grades respectively.

As the finding of a negative correlation between these rates is of some importance, we examined the effects of excluding $(a)$ long durations, since relatively few of these episodes might have a marked effect, and $(b)$ uncertified episodes, which may be qualitatively different from certified ones. The correlations 
TABLE 8

SICK PERSON RATE AND DURATION PER EPISODE OF GRADES

\begin{tabular}{|c|c|c|c|c|}
\hline \multirow{2}{*}{$\begin{array}{l}\text { Standardized } \\
\text { Average Duration } \\
\text { per Episode }\end{array}$} & \multicolumn{4}{|c|}{ Standardized Sick Person Rate } \\
\hline & $0.06-0.24$ & $0.24-0.29$ & $0.29-0.37$ & $0.37-0.48$ \\
\hline $35 \cdot 6-21 \cdot 29$ & $\begin{array}{l}\text { Permanent way inspector } \\
\text { Luggage room attendant }\end{array}$ & $\begin{array}{l}\text { Shedman } \\
\text { Stationmaster } \\
\text { Lengthman } \\
\text { Locomotive fireman }\end{array}$ & & Shop officeman \\
\hline $20 \cdot 75-18 \cdot 96$ & $\begin{array}{l}\text { Carriage and wagon } \\
\text { examiner } \\
\text { Signalman } \\
\text { Ganger }\end{array}$ & $\begin{array}{l}\text { Timekeeper } \\
\text { Head shunter }\end{array}$ & Running shift foreman & Yard inspector \\
\hline $18 \cdot 61-15 \cdot 74$ & Locomotive driver & & $\begin{array}{l}\text { Locomotive fitter } \\
\text { Workshop labourer } \\
\text { Shunter (goods) }\end{array}$ & $\begin{array}{l}\text { Stores issuer } \\
\text { Clerk }\end{array}$ \\
\hline $14 \cdot 13-9 \cdot 48$ & Pattern maker & Telegraph lineman & $\begin{array}{l}\text { Senior clerk } \\
\text { Chief clerk }\end{array}$ & $\begin{array}{l}\text { Chief controller } \\
\text { Control staff } \\
\text { Goods porter }\end{array}$ \\
\hline
\end{tabular}

remained negative in both cases, being -0.36 and -0.16 respectively.

It may therefore be said that generally a grade has either a comparatively large number of people with short sickness episodes, i.e., the "sick-well" grades in the fourth quadrant such as goods porter and chief clerk, or a smaller number of people with comparatively longer episodes, i.e., the "well-sick" grades in the second quadrant such as permanent way inspector and shedman. In only a few instances can we consider a grade to be entirely sick or well; most grades are intermediate.

Relation of Sickness Absence Patterns to Certain Characteristics of Grades.-We now turn our attention to some features that may throw light on the causal relations underlying the negative correlations. We shall examine the sick person rate and that of average duration per episode in relation to the grade characteristics given in Table 1.

From Table 1 it is clear that the grades can be arranged along two dimensions concerned respectively with responsibility and conditions of work.

Responsibility.-This can be conveniently rated on a four-point scale with the following definitions:

\begin{tabular}{c|l}
\hline Rating & \multicolumn{1}{c}{ Grades Characterized as: } \\
\hline 1 & (a) With little or no responsibility \\
2 & (b) Routine work-little or no initiative required \\
& (a) Some measure of responsibility \\
3 & (b) More or less routine but requiring some measure of \\
& (a) Carrying considerable degree of responsibility \\
4 & (b) Requiring considerable measure of initiative \\
& Administrative or supervisory, requiring considerable \\
& measure of initiative and mental responsibility
\end{tabular}

Conditions of Work.-This dimension can be conveniently considered in three categories as follows:

\begin{tabular}{c|l}
\hline Category & \multicolumn{1}{c}{ Grades Characterized as: } \\
\hline A & (a) Manual: exposed to weather \\
B & $\begin{array}{l}\text { (b) Administrative and supervisory: exposed to weather } \\
\text { Manual: sheltered from weather } \\
\text { Sedentary }\end{array}$ \\
\hline
\end{tabular}

The grades and their ratings and categories are given in Table 9. It will be clear that these ratings are extremely crude categories and the dimensions themselves are defined only in the general terms given to us by British Railways' officials themselves. In this preliminary survey we made no attempt to refine the definitions or their categories, or to obtain empirical data on them. In such conditions only general indications can be revealed and correlation techniques are inappropriate as they are too elaborate for the data available.

There seems to be a clear relationship between conditions of work and the sick person and the duration per episode rates. The sick person rate is greatest in the least exposed conditions, while the duration per episode is highest where the exposure is greatest. In the ranking for the sick person rate (Table 9A) only one out of seven in the first quartile is exposed to the weather. On the other hand, in the first quartile of Table 9B (duration per episode) five out of seven are exposed to the weather, and in the fourth quartile (short duration per episode) only one out of seven.

The examination of the effect of responsibility shows that there is little or no change with the duration per episode, but that the sick person rate reveals some differences with responsibility. The rate is highest in the grades with least responsibility and vice versa. Thus in the first quartile (high rates) five out of seven have limited or no responsibility, while in the fourth quartile (low rates) five out of seven have substantial responsibility.

Our results in this sub-section, as far as they go, 
TABLE 9

CERTAIN CHARACTERISTICS OF GRADES

\begin{tabular}{|c|c|c|c|c|c|c|c|}
\hline Grade & $\begin{array}{l}\text { Rank for } \\
\text { Measure } \\
\text { (Table 7) }\end{array}$ & $\begin{array}{c}\text { Responsi- } \\
\text { bility } \\
\text { Rating }\end{array}$ & $\begin{array}{l}\text { Conditions } \\
\text { of Work } \\
\text { Category }\end{array}$ & Grade & $\begin{array}{l}\text { Rank for } \\
\text { Measure } \\
\text { (Table 7) }\end{array}$ & $\begin{array}{c}\text { Responsi- } \\
\text { bility } \\
\text { Rating }\end{array}$ & $\begin{array}{c}\text { Conditions } \\
\text { of Work } \\
\text { Category }\end{array}$ \\
\hline $\begin{array}{l}\text { A. Sick Person } \\
\text { First Quartile } \\
\text { Yard inspector } \\
\text { Control staff } \\
\text { Goods porter } \\
\text { Chief controller } \\
\text { Shop officeman } \\
\text { Clerk } \\
\text { Stores issuer } \\
\text { Second Quartile } \\
\text { Workshop labourer } \\
\text { Senior clerk } \\
\text { Shunter (goods) } \\
\text { Chief clerk } \\
\text { Locomotive fitter } \\
\text { Running shift foreman }\end{array}$ & $\begin{array}{c}1 \\
2 \\
3 \frac{1}{2} \\
3 \frac{1}{2} \\
5 \\
6 \\
7 \\
\\
8 \\
9 \\
10 \\
11 \\
12 \frac{1}{2} \\
12 \frac{1}{2}\end{array}$ & $\begin{array}{l}4 \\
2 \\
1 \\
3 \\
1 \\
1 \\
2 \\
1 \\
2 \\
2 \\
3 \\
3 \\
4\end{array}$ & $\begin{array}{l}\mathbf{A} \\
\mathbf{C} \\
\mathbf{B} \\
\mathbf{C} \\
\mathbf{C} \\
\mathbf{C} \\
\mathbf{B} \\
\mathbf{B} \\
\mathbf{C} \\
\mathbf{A} \\
\mathbf{C} \\
\mathbf{B} \\
\mathbf{A}\end{array}$ & $\begin{array}{l}\text { Third Quartile } \\
\text { Shedman } \\
\text { Lengthman } \\
\text { Telegraph lineman } \\
\text { Timekeeper } \\
\text { Stationinaster } \\
\text { Head shunter } \\
\text { Locomotive Fireman } \\
\text { Fourth Quartile } \\
\text { Carriage and wagon } \\
\text { examiner } \\
\text { Locomotive driver } \\
\text { Pattern maker } \\
\text { Signalman } \\
\text { Permanent way inspector } \\
\text { Ganger } \\
\text { Luggage room attendant }\end{array}$ & $\begin{array}{l}15 \\
15 \\
15 \\
17 \frac{1}{2} \\
17 \frac{1}{2} \\
19^{2} \\
20\end{array}$ & $\begin{array}{l}1 \\
1 \\
3 \\
1 \\
4 \\
4 \\
3 \\
2\end{array}$ & $\begin{array}{l}\mathbf{A} \\
\mathbf{A} \\
\mathbf{A} \\
\mathbf{C} \\
\mathbf{A} \\
\mathbf{A} \\
\mathbf{A}\end{array}$ \\
\hline $\begin{array}{l}\text { B. Average Duration per Episode } \\
\text { First Quartile } \\
\text { Permanent way inspector } \\
\text { Shedman } \\
\text { Luggage room attendant } \\
\text { Stationmaster } \\
\text { Lengthman } \\
\text { Shop officeman } \\
\text { Locomotive fireman }\end{array}$ & $\begin{array}{l}1 \\
2 \\
3 \\
4 \\
5 \\
6 \\
7\end{array}$ & $\begin{array}{l}4 \\
1 \\
2 \\
4 \\
1 \\
1 \\
2\end{array}$ & $\begin{array}{l}\mathbf{A} \\
\mathbf{A} \\
\mathbf{B} \\
\mathbf{A} \\
\mathbf{A} \\
\mathbf{C} \\
\mathbf{A}\end{array}$ & $\begin{array}{l}\text { Third Quartile } \\
\text { Locomotive driver } \\
\text { Locomotive fitter } \\
\text { Stores issuer } \\
\text { Clerk } \\
\text { Workshop labourer } \\
\text { Shunter (goods) }\end{array}$ & $\begin{array}{l}15 \\
16 \\
17 \\
18 \\
19 \\
20\end{array}$ & $\begin{array}{l}3 \\
3 \\
2 \\
1 \\
1 \\
2\end{array}$ & $\begin{array}{l}\mathbf{A} \\
\mathbf{B} \\
\mathbf{B} \\
\mathbf{C} \\
\mathbf{B} \\
\mathbf{A}\end{array}$ \\
\hline $\begin{array}{l}\text { Second Quartile } \\
\text { Carriage and wagon } \\
\text { examiner } \\
\text { Signalman } \\
\text { Timekeeper } \\
\text { Running shift foreman } \\
\text { Ganger } \\
\text { Head shunter } \\
\text { Yard inspector }\end{array}$ & $\begin{array}{r}8 \\
9 \\
10 \\
11 \\
12 \\
13 \frac{1}{2} \\
13 \frac{1}{2}\end{array}$ & $\begin{array}{l}2 \\
3 \\
1 \\
4 \\
3 \\
3 \\
4\end{array}$ & $\begin{array}{l}\mathbf{A} \\
\mathbf{B} \\
\mathbf{C} \\
\mathbf{A} \\
\mathbf{A} \\
\mathbf{A} \\
\mathbf{A}\end{array}$ & $\begin{array}{l}\text { Fourth Quartile } \\
\text { Senior clerk } \\
\text { Chief controller } \\
\text { Pattern maker } \\
\text { Telegraph lineman } \\
\text { Chief clerk } \\
\text { Control staff } \\
\text { Goods porter }\end{array}$ & $\begin{array}{l}21 \\
22 \\
23 \\
24 \\
25 \\
26 \\
27\end{array}$ & $\begin{array}{l}2 \\
3 \\
3 \\
3 \\
3 \\
2 \\
1\end{array}$ & $\begin{array}{l}\text { C } \\
\mathbf{C} \\
\mathbf{B} \\
\mathbf{A} \\
\mathbf{C} \\
\mathbf{C} \\
\mathrm{B}\end{array}$ \\
\hline
\end{tabular}

disclose the importance of both physical and psychological characteristics in sickness absence. The latter will be discussed further in relation to the three different levels of responsibility among the clerical grades in a further communication (Pugh et al., 1959).

The Extreme Grades.-The three "sick-sick" grades, i.e., those high on both measures, namely, shop officeman, yard inspector, and running shift foreman, and the "well-well" grades (those low on both measures) namely pattern maker, telegraph linesman, and locomotive driver, by those very facts merit further investigation. How far are these characteristics due to the nature of the work? How far do the "well-well" grades maintain their standards by shedding workers who fall sick? Are the "sicksick" grades such as to tolerate more and longer absences without impairing efficiency and, if so, do they receive sick workers from other grades? These are some of the questions towards which further investigation will have to be directed.

Job Change due to Sickness. - Our information on job changes due to illness was subdivided according to whether the change was $(a)$ instigated by the management, or (b) made at the request of the worker. Some of the receiving grades do not appear on our list of 27 grades, because they are jobs outside the scope of the railway research population although within the railway service.

There were 28 transfers by management and 13 at the request of the worker, due to sickness. Among these there were eight transfers within the same grade, leaving 26 grade-to-grade transfers by management and seven at "own request". These have been summarized in Table 10 .

TABLE 10

JOB CHANGES DUE TO SICKNESS

\begin{tabular}{|c|c|c|c|}
\hline $\begin{array}{l}\text { By Management } \\
\text { From: } \\
\text { Locomotive fireman } \\
\text { Locomotive driver } \\
\text { Signalman } \\
\text { Workshop labourer } \\
\text { Chief controller } \\
\text { Others }\end{array}$ & $\begin{array}{l}3 \\
7 \\
5 \\
4 \\
1 \\
6\end{array}$ & $\begin{array}{l}\text { At Own Request } \\
\text { From: } \\
\text { Locomotive fireman } \\
\text { Workshop labourer } \\
\text { Shunter (goods) } \\
\text { Head shunter } \\
\text { Stationmaster } \\
\text { Permanent way inspector }\end{array}$ & $\begin{array}{l}2 \\
1 \\
1 \\
1 \\
1\end{array}$ \\
\hline Total & 26 & Total & 7 \\
\hline $\begin{array}{l}\text { To: } \\
\text { Shedman } \\
\text { Goods porter } \\
\text { Workshop labourer } \\
\text { Clerk } \\
\text { Stores issuer } \\
\text { Yard inspector } \\
\text { Grades outside the survey }\end{array}$ & $\begin{array}{l}8 \\
3 \\
3 \\
3 \\
2 \\
1 \\
6\end{array}$ & $\begin{array}{l}\text { To: } \\
\text { Shedman } \\
\text { Clerk } \\
\text { Goods porter } \\
\text { Shunter } \\
\text { Grades outside the survey }\end{array}$ & $\begin{array}{l}2 \\
2 \\
1 \\
1 \\
1\end{array}$ \\
\hline Total & 26 & Total & 7 \\
\hline
\end{tabular}


An interesting feature of the transfers not shown in the table is that the management transferred eight of the footplatemen (locomotive firemen and locomotive drivers) to shedmen, while both the locomotive firemen who transferred at their own request also went to shedmen. It is also worthy of note that the grade of workshop labourer is the only grade to lose and receive workers.

Grades which customarily accept workers transferred from other grades on grounds of health are referred to by British Railways as "accommodation grades".

Table 11 gives further information on the grades which receive workers transferred on grounds of ill health. The "accommodation" rate of the receiving grades has been calculated by taking the total number of people entering as a percentage of the number already in the grade.

TABLE 11

RECEIVING GRADES

\begin{tabular}{l|c|c|c}
\hline & $\begin{array}{c}\text { Accommo- } \\
\text { dation Rate }\end{array}$ & $\begin{array}{c}\text { Rank Order } \\
\text { by Mean } \\
\text { Age }\end{array}$ & $\begin{array}{c}\text { Rank Order } \\
\text { by Average } \\
\text { Duration } \\
\text { per Person }\end{array}$ \\
\hline 1. Shedman & $2 \cdot 7$ & 15 & 3 \\
2. Goods porter & $2 \cdot 3$ & 15 & 5 \\
3. Stores issuer & $0 \cdot 7$ & 10 & 6 \\
4. Clerk & $0 \cdot 3$ & 24 & 7 \\
5. Workshop labourer & $0 \cdot 3$ & 14 & 4 \\
6. Yard inspector & $0 \cdot 08$ & 1 & 2 \\
7. Shunter & 0.002 & 25 & 9 \\
\hline
\end{tabular}

Shedmen and goods porters are frequently used as receiving grades and they may be considered to be "accommodation" receiving grades, while the others, although receiving some transfers, cannot really be so regarded.

A notable characteristic of all these grades is that they are "sick" grades comprising seven of the nine grades within the highest third on average duration per person rate. It is thus probable that not only do they retain their own sick men, but they accept sick workers from other grades less able to tolerate sickness absences. These grades will therefore be selected for further detailed study in the follow-up survey.

From the data at present available to us there does not seem to be an age trend in the job changes due to sickness.

More Suitable Grades for Older Workers. - Certain grades may be more suitable for older workers. We have conducted a detailed age analysis of the railway research population (see Gordon, Emerson, and Pugh, 1959) and on this basis tentatively identified four grades as being possibly more suitable for older workers in view of their high age distribution. These were timekeeper, luggage room attendant, stores issuer, and shop officeman. The fact that the mean age of men in a particular occupation is high does not of itself imply that it is a more suitable occupation for older workers, but it does at least indicate that such jobs are being "held down" by them. It is obviously relevant to consider the sickness absence experience of these particular grades.

The grade of shop officeman is the only one of the four which lies in the "sick-sick" quadrant of Table 8. It provides sedentary routine work in which little or no initiative is required (Table 1 , No. 18). If it is a "sick" grade because it retains its own sick members and absorbs others, it would be expected to show up as one of the grades to which people are transferred. In fact this is not the case from our own data. We cannot, on this basis alone, reject the possibility of it doing so, for on our returns covering one year the numbers transferred are small and the grade consists of only 100 people. There may have been no vacancies in this grade during the period of study; for example, the grade may have received too extensively during the preceding period. Clearly the grade of shop officeman must be investigated further.

Stores issuer and timekeeper fall into different squares from one another (Table 8), but both are adjacent to the "sick-sick" quadrant. Stores issuer also ranks high on the average duration per person measure and is shown to be a grade into which people are transferred on account of sickness. Timekeeper has no people transferred to it, but it is a small grade and so might not show the effect over the period concerned. Luggage room attendant is a complete anomaly, since it has a very high duration per episode and a very low sick person rate. It has the lowest average duration per person.

One of the outstanding features of the railway research population is the very large size of the operating grades, the footplatemen and the signalmen, and the very small size of what we have tentatively identified as grades into which they might transfer. Provision for the large number of older workers would indeed present many difficulties. It should not be concluded that our account covers all the provision that is made. The present examination has not encompassed changes within the existing grades; for example, whether and in what state of health locomotive drivers are transferred from the more strenuous to the less strenuous, or from the more responsible to the less responsible, runs. This further information is not available from our present records.

\section{Discussion and Conclusions}

Certain main points may be made on the basis of the data which have been presented. 
When sheer number of episodes is the criterion of the amount of sickness absence, the railway research population compares favourably with other populations studied. On the other hand, when duration per episode is the index, the railway research population shows a higher figure at all ages than the only other population with which we have been able to compare it. It may well be that the greater tendency to long durations of sickness in the railway research population is due to the type of working conditions.

This view is supported by our analysis of age standardized rates for the various grades, and of the relation of sickness absence patterns to responsibility and conditions of work. On the first point, we conclude that the differences due to grades are at least as striking as those due to age; on the second, that duration of sickness episode is greatest where exposure to the weather is greatest. Examination of Table 1 shows that 13 grades (representing 7,520 men) are classed as exposed to the weather, compared with 14 grades (representing 6,554 men) which are classed as sheltered from the weather. A comparison of the corresponding proportions in the London Transport population would help in. elucidating this point. As far as the railway research population is concerned, a much closer examination of the conditions of work, psychological no less than physical, is required.

Closely related is the negative correlation we have reported between the sick person rate and the duration per episode for the various grades. Our conclusion is that a grade has either a comparatively large number of people with short sickness episodes, or a smaller number of people with comparatively longer episodes. Some preliminary analysis of the kind of variables which may underlie this state of affairs has been carried out. But again, a much more detailed analysis, especially of the psychological aspects of the work involved in each grade, is required before the reasons for this observation can be elucidated.

The exclusion of the uncertified episodes has the effect of drastically reducing this correlation. Some data bearing on this point will be presented in a later report. The possible implications of the uncertified sickness data are discussed below.

The sickness pattern of the age groups is similar in form to that commonly found, namely, that in the older age groups the episode rates tend to be only slightly higher than at younger age groups, but that the episodes of the older men tend to be longer. Here too, considerable amplification is necessary. A first step would be the examination of the age distributions for the diagnoses recorded at the time of the sickness episode. The direction of subsequent investigation would depend on the nature of these distributions, but ultimately an analysis of the whole question of sickness thresholds and the complex of pressures effective at the onset, during, and at the end of an episode would be required.

The pattern resulting when our five types of sickness duration are analysed by day of starting sickness lends itself to interpretation in terms of "morale". Such an interpretation has been discussed, but it is, in effect, a series of hypotheses, all of which need to be tested by psycho-social investigations. In examining what happens when a man takes sick leave, it is important to consider not only the nature of his sickness, his working conditions, and his general attitude to his job, but also the nature of family pressures to remain at work, loyalty to the working group, and other factors. In the main, our data at present are consistent with an interpretation that for whatever reason, men who will eventually take sick leave, often for a longer period, do attempt to carry on working to the end of the week in which they first begin to feel ill.

This work was started with encouragement from the Human Relations Committee of the Department of Scientific and Industrial Research and the Medical Research Council. We are grateful to the Medical Research Council for a grant in aid.

We are happy to acknowledge the very great help of the Establishment and Staff Office of the Scottish Region of British Railways through Mr. C. H. Brazier, Mr. D. F. Gowan, Mr. J. Weston, and Mr. D. Murray. We are also grateful to Dr. W. A. R. Mailer and Dr. J. D. Galletly of the Medical Department. The work has had the friendly interest of the trade unions concerned. We have had much assistance from Gene McKinnon, Patricia Taylor, and Jane Walsh (research auxiliaries), John Nimmo (Hollerith technician), and Gertrude Cleary (clerk).

\section{REFERENCES}

Behrend, H (1951). Absence Under Full Employment. University of Birmingham. Studies in Economics and Society. Monograph A 3 .

General Register Office (1954). 1. Measurement of Morbidity. Studies on Medical and Population Subjects No. 8. H.M.S.O., London.

England and Wales. Report. 1911.

Gordon, C., Emerson, A. R., and Pugh, D. S. (1959). "The Age Structure of Scottish Railwaymen", Popul. Stud., 12, 223.

Hill, A. Bradford (1929). J. roy. Stat. Sóc., 92, 183.

London Transport Executive (1956). Health in Industry. Butterworths, London.

Ministry of Pensions and National Insurance (1953-54). Digest of Statistics Analysing Certificates of Incapacity 1953-54. London. (1956). Report. H.M.S.O., London.

Pugh, D. S., Gordon, C., and Lëvy, K. (1959). "Sickness Absence Among Railway Clerical Workers." Brit. J. industr. Med. To be published. 